\title{
Male and female faculty members' perceptions of organisational culture in academic medicine at 26 representative US academic health centres: implications for delivering the future hospital
}

\author{
Authors: Linda Pololi, ${ }^{A}$ Arthur Evans, ${ }^{B}$ Jan Civian ${ }^{A}$ and Robert Brennan ${ }^{C}$
}

\section{Aim}

Vital and productive academic faculty are critical to the future hospital, yet studies indicate high dissatisfaction and burnout, and a lack of advancement and senior roles for women. This study sought to identify personal and cultural factors associated with vitality and intention to leave academic medicine, and similarity and dissimilarity between perceptions of the culture by male and female faculty, and racial/ethnic minority faculty (URMM).

\section{Methods}

The C - Change Faculty Survey was used to collect data on perceptions of organisational culture in a stratified random sample of 4,578 full-time faculty in a stratified randomly selected sample of 26 US medical schools during 2007-9. The survey asked about advancement, engagement, relationships, collaboration, diversity and equity, leadership, mentoring, institutional values and practices, and work-life integration. Factor analysis and expert review created scales assessing 12 dimensions of the culture, which served as the key outcomes. Regression analysis identified gender and minority differences while controlling for other demographic characteristics.

\section{Results}

2,381 faculty responded (52\%); 1,271 (53\%) were female, and 512 (23\%) were URMM. Faculty valued their work, but 273 (14\%) had seriously considered leaving their own institution and $421(21 \%)$ leaving academic medicine altogether owing to dissatisfaction; an additional 109 (5\%) cited personal/family reasons. Negative perceptions of the culture - unrelatedness, feeling moral distress at work, and lack of engagement - were associated with leaving for dissatisfaction $(\mathrm{p}<0.001)$. Other significant predictors were perceived values incongruence, low institutional support, and low self-efficacy. Institutional characteristics, gender and minority status were not predictive of attrition. Compared with men, female faculty reported lower perceptions of belonging and relationships $(\mathrm{p}<0.01)$, self-efficacy for career advancement $(p<0.001)$ and gender equity $(\mathrm{p}<0.001)$. Women were less likely than men to believe that their institutions were making changes to address diversity goals $(\mathrm{p}<0.001)$, that their institution was family friendly $(\mathrm{p}<0.001)$, and women reported less congruence between their own values and those of their institutions $(p<0.05)$. Women and men did not differ significantly on levels of vitality, leadership aspirations, or ethical/moral distress.

\section{Conclusions}

Findings suggest that American academic medicine does not support relatedness and a moral culture for many faculty. Faculty men and women have equal levels of engagement and leadership aspirations. However, medical schools have failed to create and sustain an environment where women feel fully accepted and supported to succeed. Enhancing faculty vitality requires more attention to strengthening relationships, the misalignment between faculty and institutional values, and improving work-life integration.

\section{Conflict of interest statement}

There are no conflicts of interest.
Authors: ${ }^{A}$ Brandeis University, Waltham, MA, USA; ${ }^{B}$ Weill Cornell Medical College, New York, NY, USA; 'Harvard University, Cambridge, MA, USA 